\title{
The rôle of the Kokino megalith in the life of the Bronze age agricultural community
}

\author{
Gjore Cenev \\ MKC Planetarium, \\ 1000 Skopje, Kej Dimitar Vlahov bb, \\ Former Yugoslav Republic of Macedonia \\ email: mkc@mt.net.mk
}

\begin{abstract}
In 2002 in the region of North-East Macedonia a site was discovered, for which archaeoastronomical analyses have shown that it encompasses all elements of an ancient observatory dated $2000 \mathrm{BCE}$. In line with the analysis the existence of a central position, from where Sunrises and rises of Full Moon were observed, was confirmed, as well as that in the rocks on the east horizon a markers were crafted marking the places of the rise of the Sun and Moon in exactly determined days. From this central position, total 9 markers can be seen on the east horizon, 3 of which used to mark the places of the Sunrise in the course of the year, and remaining 6 marked the places of Full Moon rise. By continuous monitoring of the periodicity of the Full Moon rise, ancient sky observers could develop 19 years periodic lunar calendar. In addition, on the site there is a special observation place related to the cycles of solar and lunar eclipse. Only from there and toward the east horizon 4 markers can be seen, which were used for marking the positions of the Full Moon rise on the day of the beginning of the new periodic cycle of eclipse of 54 years and 34 days. The most outstanding content on the territory of the observatory are 4 stone seats called thrones. Also, on the east horizon there is one specially crafted marker that had ritual purpose. Archaeoastronomical analysis has shown that on the day when the harvest ends, rise of Sun could be seen exactly trough the aperture of this marker, enlightening by beam only one of the thrones where most probably a community headman was sitting. That was a ritual joining of the God Sun with the community headman and renewal of his energy as a guarantee for rich harvest in the coming year. This is just a fragment of information that Megalithic Observatory Kokino has to offer, linked with the culture and cosmological presentations of people of the early agricultural community in the Bronze Age.
\end{abstract}

Keywords. Archaeoastronomy, megaliths, agriculture

\section{Introduction}

Life of the people from the Bronze Age did not consist only of activities related to land cultivating, stock breading, shelters building and making pots and vessels, tools and weaponry. Same as at any stage of civilization development, they try to understand the world around them as ultimate creation and gift by Gods. In addition, they tried to create communication links with the Cosmos driven by the desire to acknowledge their role and purpose of existence, as well as of the need to determine and keep their position in that world in longer period. By doing so, they developed and built creative and spiritual capacities and values of the man as an individual, but at the same time of the community, which gained characteristics of that particular civilization stage of the humankind development.

In the past, life of people was particularly depended on the events occurring on the sky. Thus, people monitored those events occurring on the sky with great attention and tried to understand movements of the celestial objects especially of those influencing their life, such as that of the Sun. Therefore, in the entire written and non-written 
history of humankind civilization, there is no community where Sun is not presented as a Divinity, which is life giving and life-providing. Existence of the dimension time, as one of the four dimensions of the world, is the one that is the most difficulty to be acknowledged. Understanding the concept of time requires certain level of awareness for the self- existence, as well as awareness of the existence of time at real and physical level, as well as at abstract or metaphysical level. Measurement of time involves continuous and devoted monitoring of the nature rhythm, which at the same time is the rhythm of the divinity creation - the Cosmos. Therefore, by realizing, the process required for development of a calendar, which is based on the measurement of the periodicity of the celestial objects' movement, information related to the cosmological images of the people that lived in concrete cultural and historical period are provided.

Several thousands years ago, in the period of the Bronze Age, people lived in entire unity and harmony with the nature. Different views of the surrounding world did not exist or in other words, people of those times did not make any distinction between religion and science. Therefore, very frequently, all over the world, sites are found containing some specific characteristics that from one hand suggest religious aspects of spiritual and sacrificing rituals performed, and from the other hand representing observatories for monitoring and marking positions of the celestial objects such as Sun, Moon, Venus, Pleiades, Sirius etc. Megalithic Observatory Kokino is such type of a place.

\section{Archaeoastronomical characteristics of the Kokino megalalithic observatory}

The Kokino megalithic observatory is located on the territory of the Municipality Staro Nagoricane, in the area of the village Kokino, in the Northeastern part of the Former Yugoslav Republic of Macedonia. Contents of this ancient observatory are arranged on two scale-like platforms on the top of the rocky mountain peak with $1013 \mathrm{~m}$ altitude, right above the village Kokino (Fig. 1).

The observatory is spread on an area right beneath the mountain peak Tatikjev Kamen with the following dimensions: 90 meters in East-West direction and $50 \mathrm{~m}$ in North-South direction. Seen from a third dimensional view point, the contents of the observatory are found on two platforms: East and West. The east platform is 20 meters higher than the west platform. The geographical coordinates of the site are the following: latitude $42^{\circ} 15^{\prime} 47^{\prime \prime}$ North and East longitude $21^{\circ} 57^{\prime} 32^{\prime \prime}$. Geological analyses have shown that this is one andenzite neck (concrete lava in the volcano's channels) most probably dated in the earliest phase of the volcano activities happening in Kratovo-Zletovo area, in the time of later Pliocene (Dordevič 2003). Andenzite rocks have that natural disposition to crack in vertical and horizontal direction and to form a four-angle pillars and platforms of concrete lava. This natural structure and characteristics of the andenzite rocks surely was of great help to the ancient inhabitants while constructing and establishing this place as a Holy Mountain and Ancient Observatory.

In 2002, for the first time in Republic of Macedonia, an archaeoastronomical analysis was performed on an archeological site (Cenev 2002). In the course of the archaeoastronomical analysis of the site, recommendations and methodology of the Professor Gerald Hawkins, which he used during his archaeoastronomical analysis of the well-known site Stonehenge in England, were applied (Hawkins 1963). The analysis confirmed that this particularly interesting place has great number of contents that are typical for an ancient observatory dated in time of so-called megalithic culture. Researches has shown that places used for observing Sun and Moon are found on the lower or West platform, and all markers for marking the positions for Sun and Full Moon rise are found on the 
upper or East platform. Some of the stone markers were preserved in almost their original state, and some were evidently damaged, most probably due to the terrible earthquakes, happening on the territory of Macedonia every 500 years, in average.

In compliance with the principles of the archaeoastronomical analysis, a need occurred to find one central position from where all stone markers connected with the assumed movement of Sun and Moon on the sky could be seen. On the lower platform of the site, there are three clearly identified and treated places for which it can be assumed that were used for observing movements of the Sun and Moon. The first and the most suggestive place are the four stone seats today know as thrones, and the remaining two are crafted in such manner that only one person, in standing position, can be placed there. Analysis of all possible alignments (Fig. 2) has shown that each of those three places had special role and purpose during the undertaken observations of the Sun and the Moon.

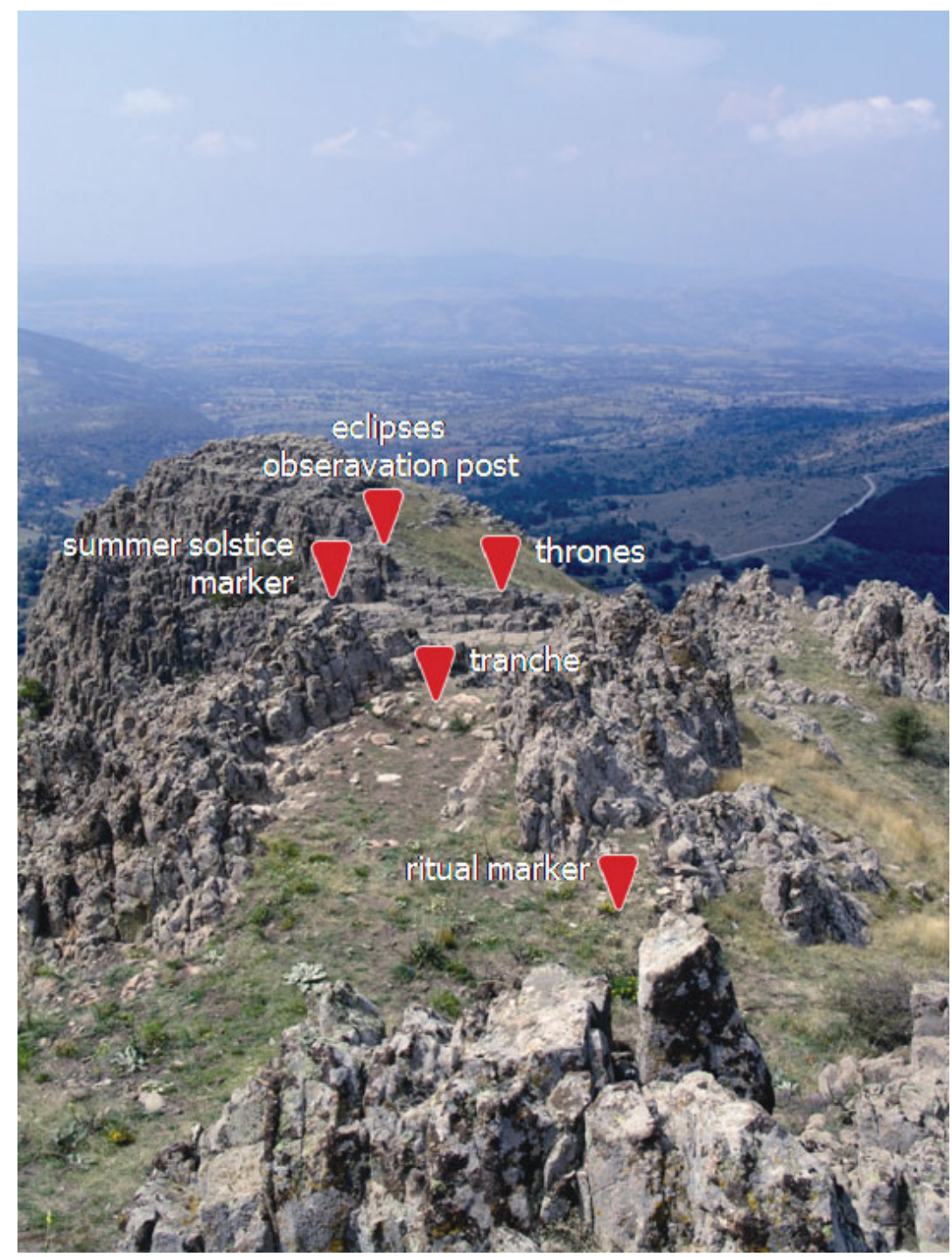

Figure 1. The Kokino site, as seen from the peak of Tatikjev Kamen. 

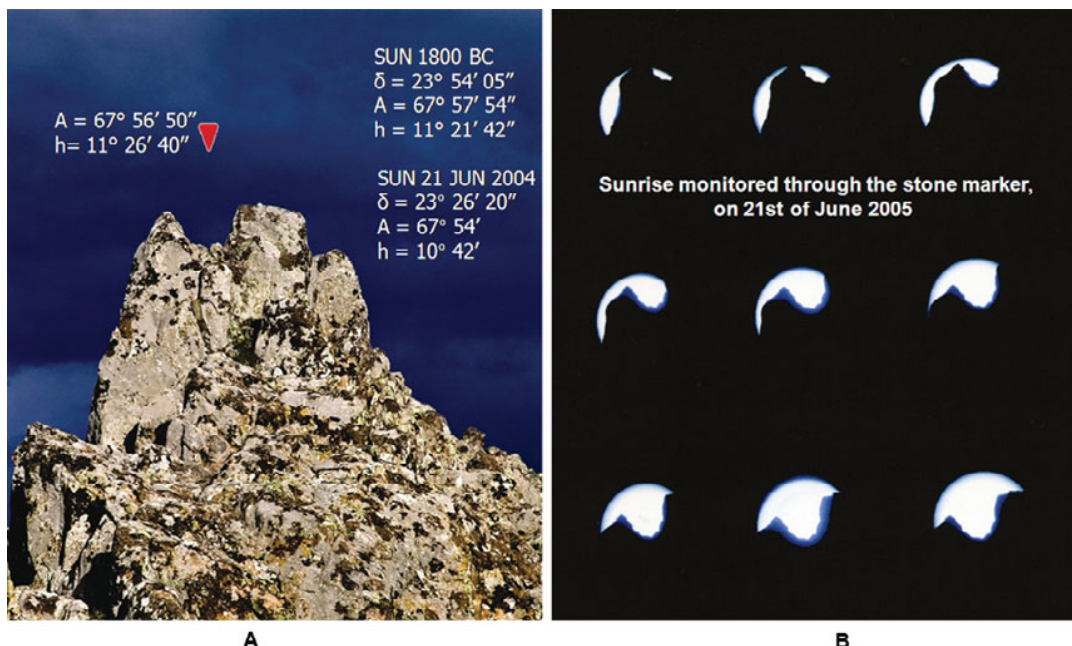

Figure 2. Organisational scheme of the area.

From the first observation post located in the rocks on the East horizon, and only from there, 9 markers can been seen, all linked with the typical places of the Sun and Full Moon rise, functional for the development of a calendar. From the second observation post on the east horizon, 4 markers can be seen, used for marking the places of Full Moon rise in the days when the Saros eclipse cycle starts. Consequently, only from one of the four stone seats- thrones, as third observation post on the east horizon, one very typical marker can be seen used for marking the place of Sunrise. This was on the day when ritually the end of harvest was celebrated, as well as the day when ritual of linking the God Sun with the community ruler was performed for the renewal of ruler's energy.

\section{Markers of the Sunrise and Full Moon rise}

The main idea of the archaeoastronomical analysis of the site was to measure horizon coordinates of all specially crafted stone markers on the East horizon, which can be seen from the observations posts on the site. Then, using the transformation formula to transfer them to the equatorial system and by calculating the values of the declination to reach a conclusion on the nature of the celestial objects whose rose was marked on the east horizon. Measurements were performed using the instrument Total Station Lajka 307 with laser, which enabled provision of results with great accuracy (Cenev 2002, 2006). The geodesist Mr. Chedomir Arsovski did the measurements, and all documented photographs, were done by the photographer Ljupco Ilievski. Results of the analysis take into account the refraction impact and celestial objects' parallaxes.

As an example of the undertaken measurements and conducted analysis, we will provide data related to the marker used for marking the place of Sunrise on the east horizon in the day of summer solstice (Fig. 3). Measurement of the horizon coordinates of the marker provided following values: Azimuth $67^{\circ} 56^{\prime} 50^{\prime \prime}$ and altitude $11^{\circ} 26^{\prime} 40^{\prime \prime}$. Based on the data, it can be calculated that the declination of the object which rose on the horizon in the past was marked by this particular marker was $23^{\circ} 9^{\prime}$. That is the declination value of the Sun in the day of summer solstice around 1800 BCE.

Due to the influence of the procession, today the declination value of the Sun in the day of summer solstice has the value of $23^{\circ} 50^{\prime}$. Thus, today in the day of summer solstice, when Sun is observed from the first observation post, which at the same time is the 

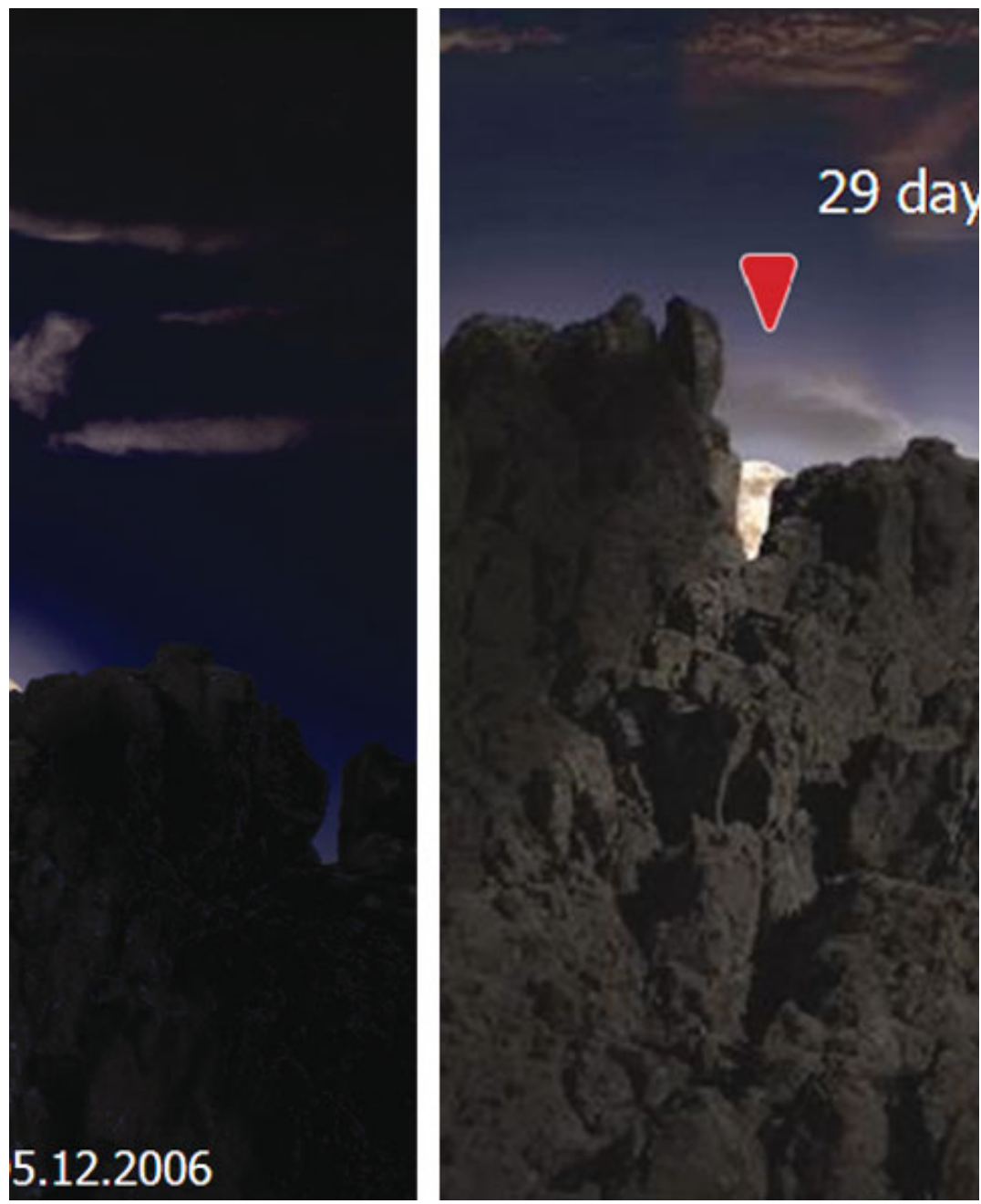

Figure 3. Marker of the solstice.

central position of the observatory, it will rise a little bit to the left and lower than in the day of summer solstice 3800 years ago. This can be seen on the photos, done during the Sunrise monitored through the stone marker, on 21st of June 2005 (Fig. 4).

Similar type of measurements, calculations and documentation were performed for all stone markers, on places that are typical for the rise of the Sun and Full Moon on the east horizon. By doing so it was possible to discover other three stone markers used to mark position of the rise of the Sun on the East horizon in the days of summer solstice, vernal and autumn equinox and winter solstice. They present evidence that ancient sky observers had solid knowledge of the apparent movement of the Sun over the sky in the course of one tropical year.

Unlike the movement of the Sun, the movement of the Moon on the sky is not a simple one, and places of the Full Moon rise on the east horizon repeat over a long periods of time. Four stone markers discovered on the site, suggest that they were used by the ancient inhabitants for marking the places of the Full Moon rise on the east horizon during the Moon winter minor and major standstill, as well as Moon summer major and minor standstill. Existence of these four markers marking the places of Full Moon rise is 


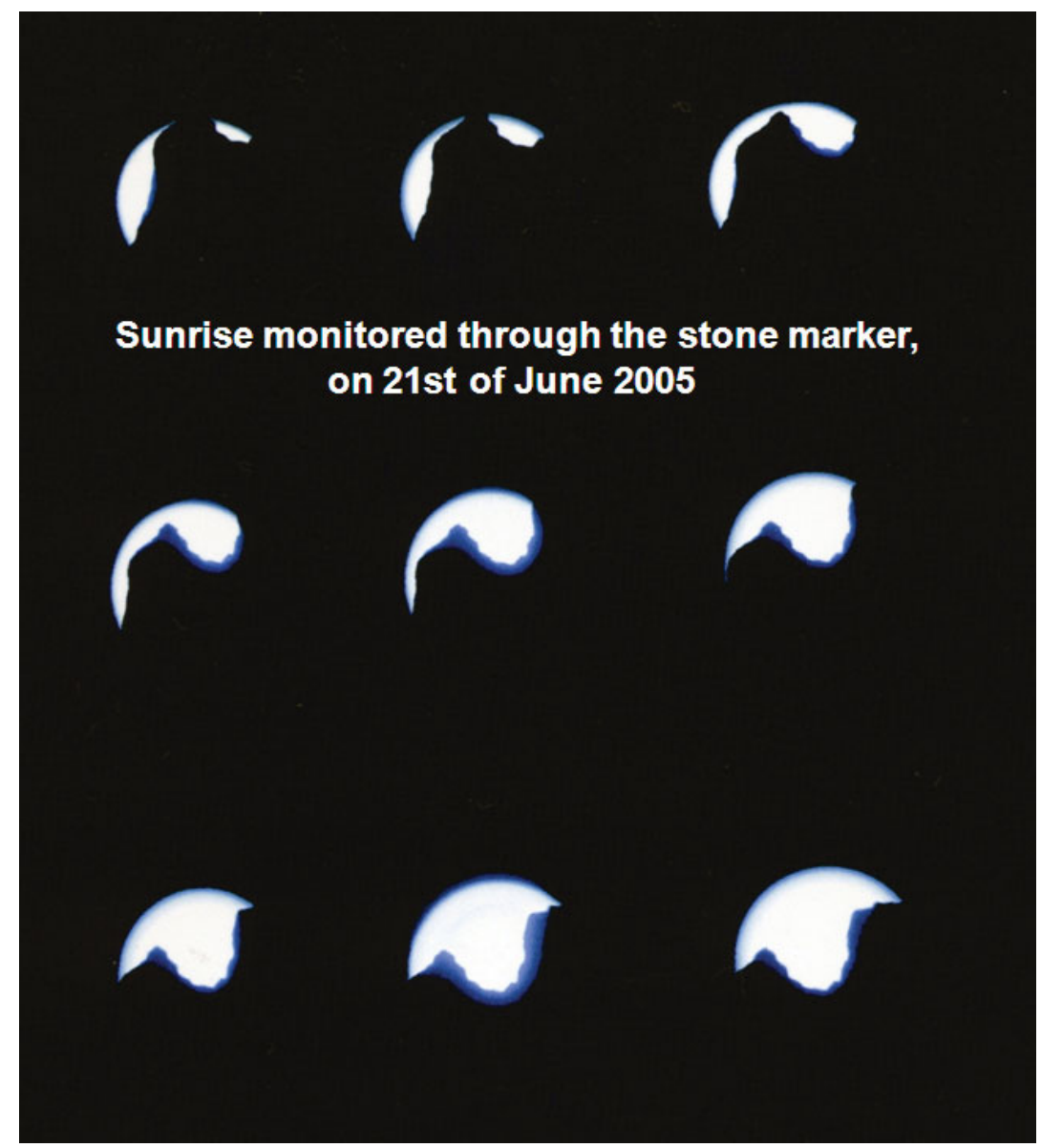

Figure 4. Sunrise seen in the day of solstice.

clear evidence that ancient sky observers knew about the 19 years' cycle, when the Full Moon will rise on the same place, in the same phase and same calendar day.

\section{Kokino calendar}

Development of a calendar was main task, but at the same time tremendous achievement of ancient sky observers and result of their creativity. Existence of stone markers confirmed the thesis that ancient observers were familiar with the apparent movement of the Sun over the sky in the course of a year, as well as apparent movement of a Full Moon in the frames of 19 years' cycle. This immediately imposed the dilemma of the type of calendar developed on this ancient observatory. Was this calendar solar, lunar or of combined type-lunar - solar calendar?

The dilemma was solved at the end of 2006 and at the beginning of 2007 when the existence of stone markers used for measurement of the lunar month with 29 and 30 days length, was confirmed (Cenev 2007). On the 5th of December 2006, on the day of the Moon winter major standstill within the cycle of 19 years, the Moonrise occurred and could be seen exactly trough the hole of the stone marker discovered in one of the previous years (Fig. 5). 


\section{Midwinter Major Moon Standstill}

\section{Moonrise on 05.12.2006}

Figure 5. Marker used to mark the Full Moon position at the beginning of the 19 years-long cycle.

In the same block of stones there is clearly noticeable and same by shape stone marker that is marking the place of Full Moon rise exactly one 1 unar month later, i.e. in context of the previous observations on 3 January 2007. Full Moon rise that could be seen trough this marker in the previously stated date was clear evidence that ancient astronomer not only knew about the Full Moon rise and about 19 years-long lunar cycle, but also they knew and accurately measured the length of the lunar month, which in the winter period is 29 days of length (Fig. 6). 


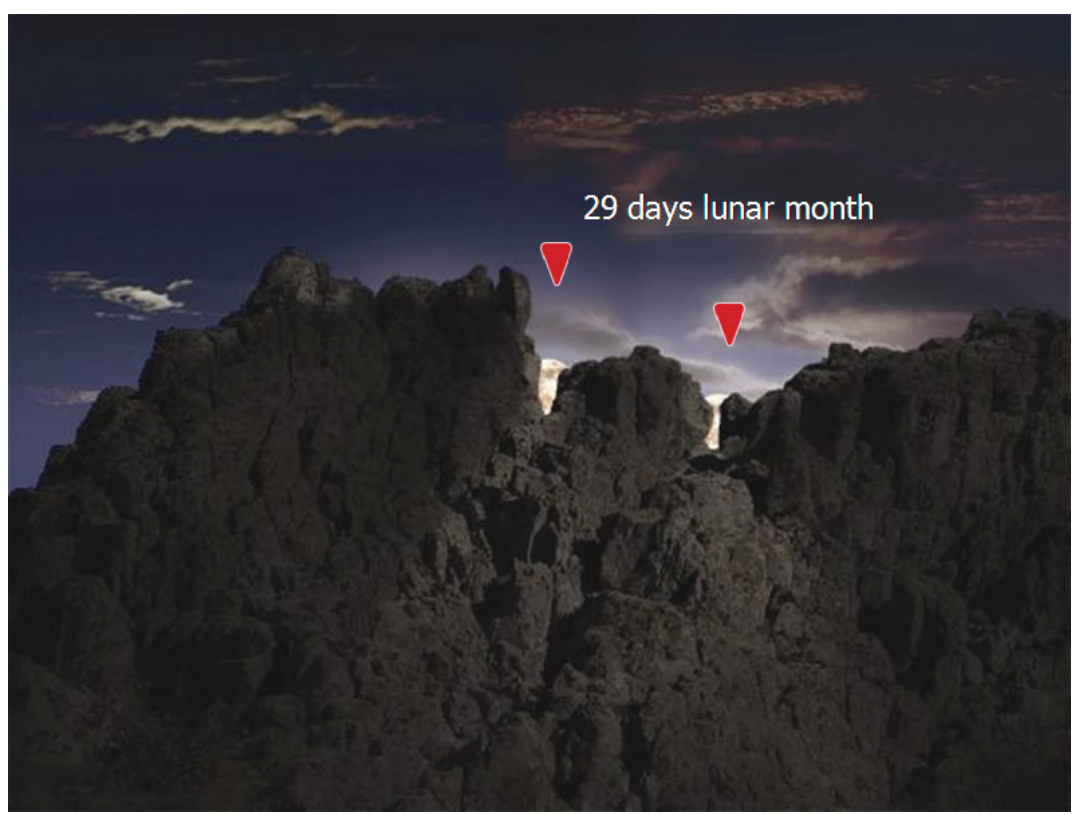

Figure 6. Measurement of the lunar month with 29 days of length.

Table 1. The tentative Kokino calendar

\begin{tabular}{rrrrr}
\hline Year & Months & Days & Tropical year & Cumulative difference \\
\hline 1 & 12 & 354 & 365 & -11 \\
2 & 13 & 384 & 365 & +8 \\
3 & 12 & 354 & 365 & -3 \\
4 & 12 & 354 & 366 & -15 \\
5 & 13 & 384 & 365 & +4 \\
6 & 12 & 354 & 365 & -7 \\
7 & 12 & 354 & 365 & -18 \\
8 & 13 & 384 & 366 & 0 \\
9 & 12 & 354 & 365 & -11 \\
10 & 13 & 384 & 365 & +8 \\
11 & 12 & 354 & 365 & -3 \\
12 & 12 & 354 & 366 & -15 \\
13 & 13 & 384 & 365 & +4 \\
14 & 12 & 354 & 365 & -7 \\
15 & 12 & 354 & 365 & -18 \\
16 & 13 & 384 & 366 & 0 \\
17 & 12 & 354 & 365 & -11 \\
18 & 13 & 384 & 365 & +8 \\
19 & 12 & 354 & 365 & -3 \\
\hline
\end{tabular}

In another block of stones there are other two similar markers where places of Full Moon rise are marked in the day of Moon summer major standstill, also showing that ancient inhabitants were not just familiar but also measured the lunar months with 30 days of length.

Taking into account all above mentioned, it was obvious that a lunar calendar with 19 years cycle was developed on the Megalithic Observatory Kokino. This calendar included certain number of lunar months with 29 days of length and certain number of lunar months with 30 days of length. The analysis of the experiences gained from the studies 
of other ancient cultures of that period of time, as well as the data related to the number of Full Moons appearances in the course of one tropical year, have shown that in the cycle of 19 years there are 12 years with 12 lunar months, which are called ordinary years, and 7 years with 13 lunar months, which are leap years.

Ethnoastronomical data of Macedonian people gathered in the course of the researches performed in the past 25 years were very helpful while analysing the lunar calendar (Cenev 2004). According to those data, even nowadays, in the villages in Macedonia people say that one calendar year has two seasons: winter and summer. In addition, it is said that in ancient times, winter months were very bad and thus were shorter, and summer months were very good and thus they had more days. In accordance to the data noted in the collective memory of the common people, conclusion can be drawn that regular years in Kokino Calendar had 6 winter months with 29 days and 6 summer months with 30 days. In the course of the leap years, there were 13 lunar months due to the fact that one summer month with 30 days of length was added. In 19 years cycle, these leap years occurred according to the specially developed pattern. In Kokino Calendar, this was according to the number of Full Moons appearances in the year, which means that every 2 nd , 5th , 8th , 10th , 13th , 16th and 18th year one lunar month with 30 days of length was added. In this manner (Table 1) a lunar calendar with 19 years' cycle was developed, today known as Kokino Calendar, which is in very good compliance with the change of seasons and length of the tropical year.

\section{Sun and Moon eclipse cycles}

Fact that movement of the Moon was very carefully observed in long periods of time on Kokino imposed the question whether ancient sky observers from Kokino were familiar with the cycles of Sun and Moon eclipses. Existing literature provides information related to the archaeoastronomical analyses of the famous sites from Megalithic period, such as Stonehenge in England (Hawkins 1963) which are focused on creating links between the number of and arrangement of stone markers in the space with the cycles of Sun and Moon eclipses (Hawkins 1964; Colton \& Martin 1967). In doing this, special efforts are made for these arrangements of the stones to be presented in a function of some kind megalithic computer used in the past for envisaging the Sun and Moon eclipses.

Archaeoastronomical analysis of the site Kokino (Cenev 2008) have shown that for observing Moon eclipses there is a special observation post crafted to be used in a standing position (Fig. 7).

Ancient observers from this post carefully monitored the rise and movement of the Full Moon. Analyses have shown that only from this place 4 easily noticeable markers can be seen on the east horizon(Fig. 8).

Measurements of the coordinates and calculations of the coordinates of the Full Moon rise have shown that with these four markers in the period from 2000 BCE up to 1700 BCE, places of Full Moon rise on the horizon in the nights when total Moon eclipse occurred were marked. Each of the markers was set after a period of 54 years and 34 days (Table 2).

Astronomy records and acknowledges Saros cycle of eclipse with 18 years 11 days and 8 hours of length. Also, it is well known fact that the same order of eclipses, on the same geographical area and in same time will repeat on every 54 years and 34 days or after three series of Saros. Concordance of the coordinates of the stone markers and coordinates of Full Moon rise places in the night of eclipses, showed that ancient observers of the sky over Kokino were very familiar with the cycles of Moon eclipses and that they continuously monitored them for more than 220 years. 


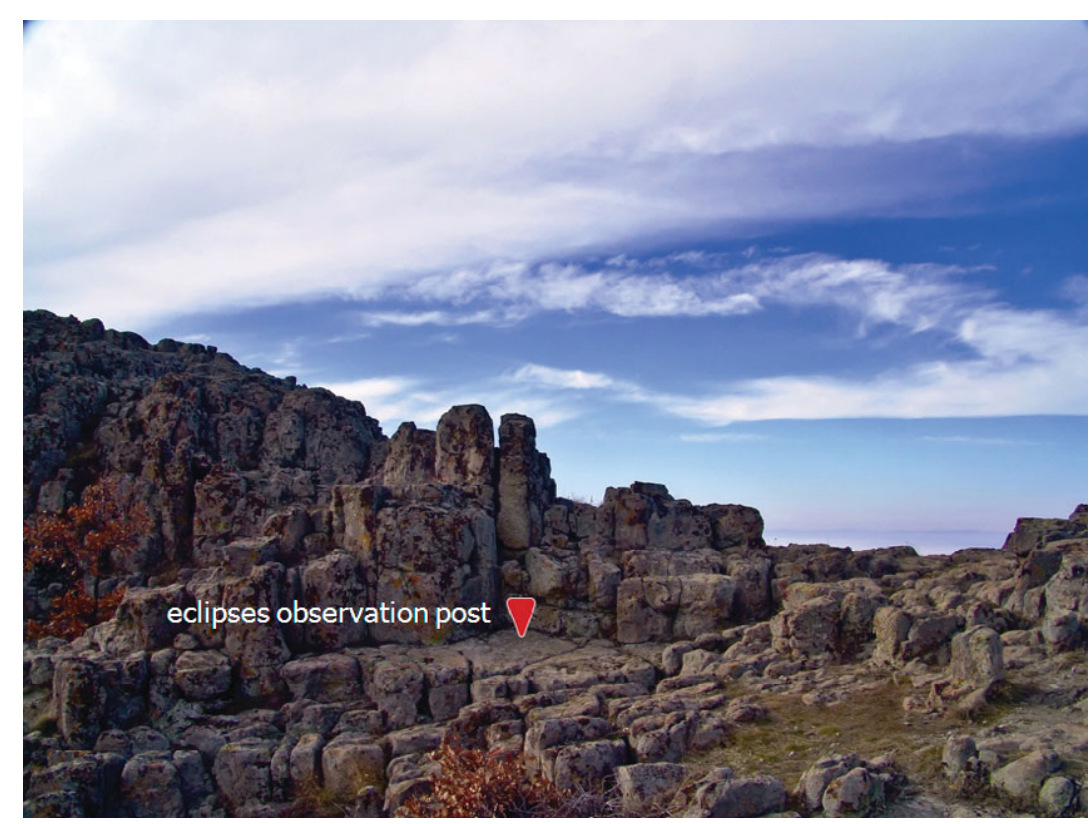

Figure 7. Observation post for the eclipses.

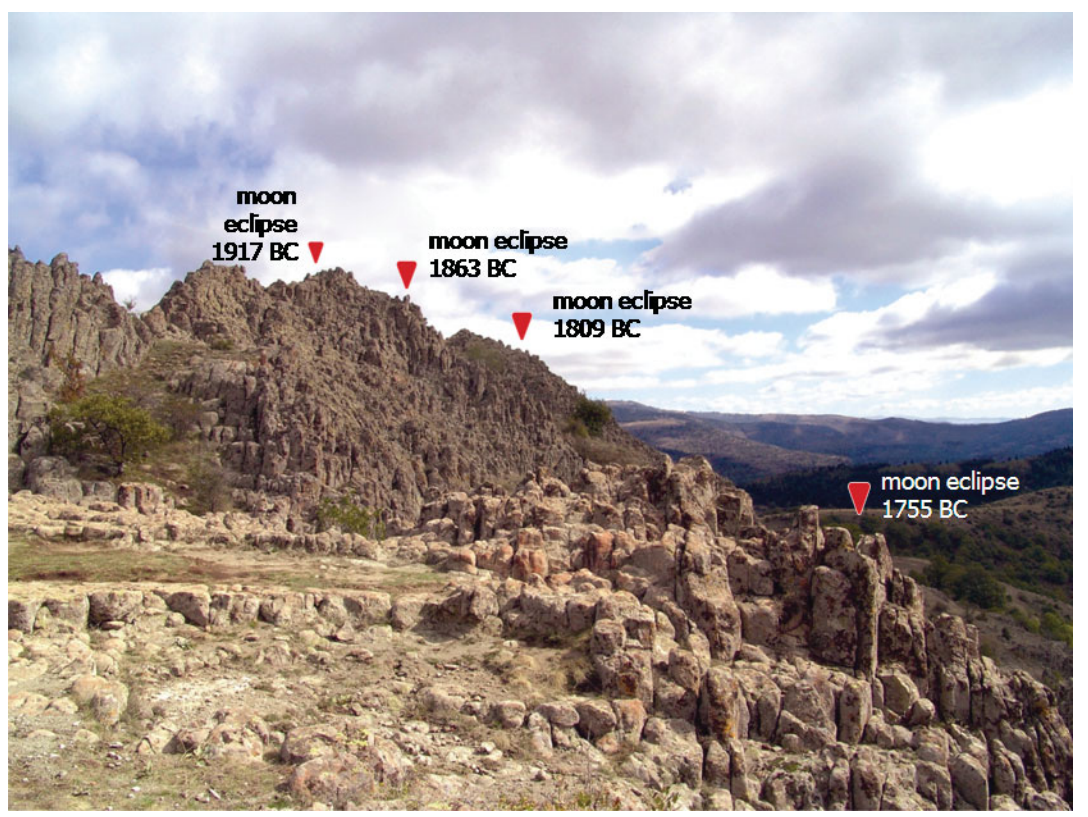

Figure 8. Markers used to mark the beginning of the eclipse cycles.

\section{Kokino observatory as a ritual place}

Archaeoastronomical analysis has shown (Cenev 2007) that on the site there is one very special stone marker (Fig. 9) used to mark the place of the Sunrise in one especially important ritual day devoted to the end of the harvest. The analysis has confirmed that Sun in the course of one year on two occasions fills the hole of the marker. 
Table 2. Coordinates of the Full Moon rise places and stone markers.

\begin{tabular}{|c|c|c|c|c|c|c|}
\hline \multirow[t]{2}{*}{ Date } & \multirow[t]{2}{*}{ Eclipse type } & \multirow[t]{2}{*}{ Saros } & \multicolumn{2}{|c|}{ Moon } & \multicolumn{2}{|c|}{ Markers } \\
\hline & & & $A$ & $h$ & & $h$ \\
\hline $\mathrm{BCE}$ & & 3 & $70^{\circ} 37^{\prime}$ & $11^{\circ} 18^{\prime}$ & $70^{\circ} 43^{\prime}$ & $10^{\circ} 4^{\prime}$ \\
\hline $1863 \mathrm{BCE}$ & To & 3 & $78^{\circ} 00^{\prime}$ & $10^{\circ} 12^{\prime}$ & $78^{\circ} 01^{\prime}$ & $9^{\circ} 50^{\prime}$ \\
\hline 30.03.1809 BCE & Total & 3 & $88^{\circ} 28^{\prime}$ & $4^{\circ} 3^{\prime}$ & $88^{\circ} 30^{\prime}$ & $3^{\circ} 54^{\prime}$ \\
\hline $01.05 .1755 \mathrm{BCE}$ & Total & 3 & $104^{\circ} 54^{\prime}$ & $2^{\circ} 40^{\prime}$ & $104^{\circ} 53^{\prime}$ & $2^{\circ} 24^{\prime}$ \\
\hline
\end{tabular}

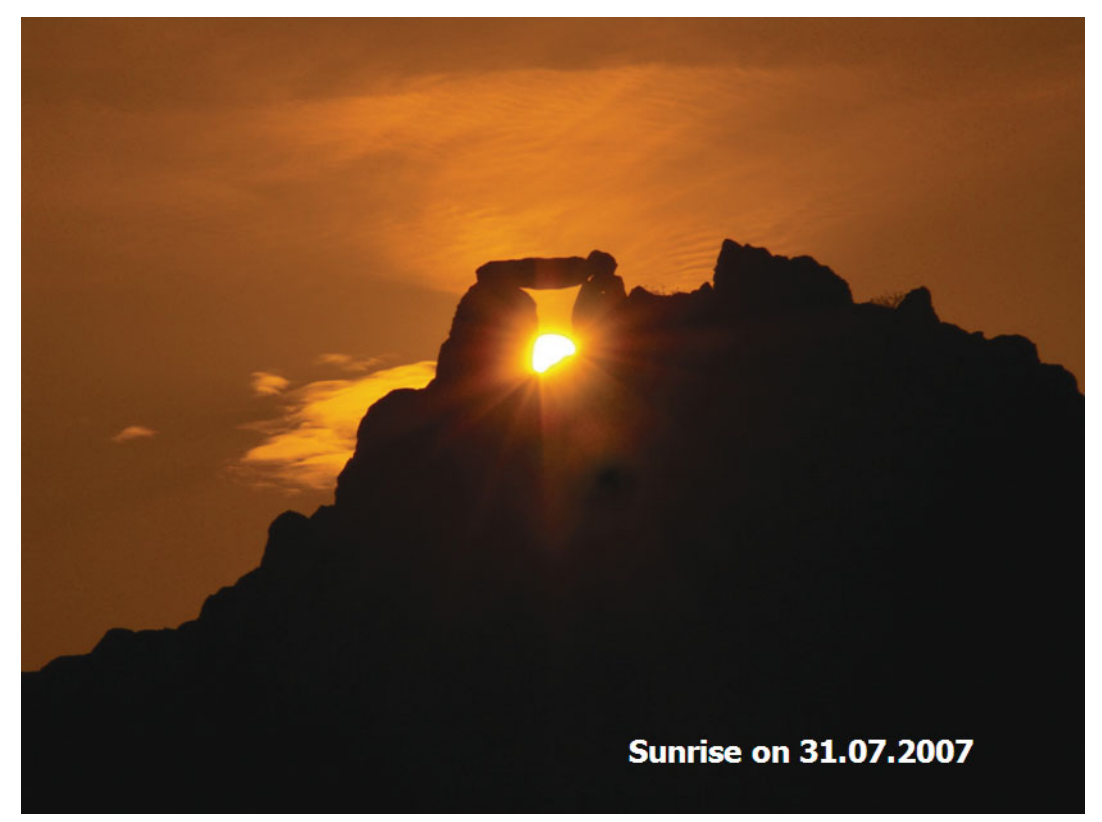

Figure 9. Sunrise seen trough the ritual marker.

The first time is in mid May, period of the year of no importance in agriculture, and the second time is at the end of July when in the ancient civilizations, but also in the contemporary one, the end of harvest is celebrated. The stone marker is crafted in the vertical rock in such a manner, that on the ritual day Sun rise entirely fills the hole of the marker, when the effect of enlightening is also occurring. Most probably in the past, this marker was covered, intensifying the effect of the sunray. The sunray was passing exactly by the right edge of the transheXXXXXXXX and fall only on one of the thrones, where in the time of the ritual, most probably the ruler of the community set (Fig. 10).

The XXXXXXXXtranshe, which is cut in the block of rocks, has great importance for the ancient observatory. Seen from the mountain peak in east-west direction, the edge of the transhe is a block of stones where the marker used to mark the Sunrise in the day of summer solstice is crafted, and right edge is cut in exact width so the sunray from the ritual marker fall only on one of the thrones. Confirmation of the fact that it is about the day when the end of harvest was celebrated is found in great number of hand wheat mills (Fig. 11) found by the archaeologists (Stankovski \& Trajkovska 2007) right beneath the foot of the rock, on which top this marker is crafted. 


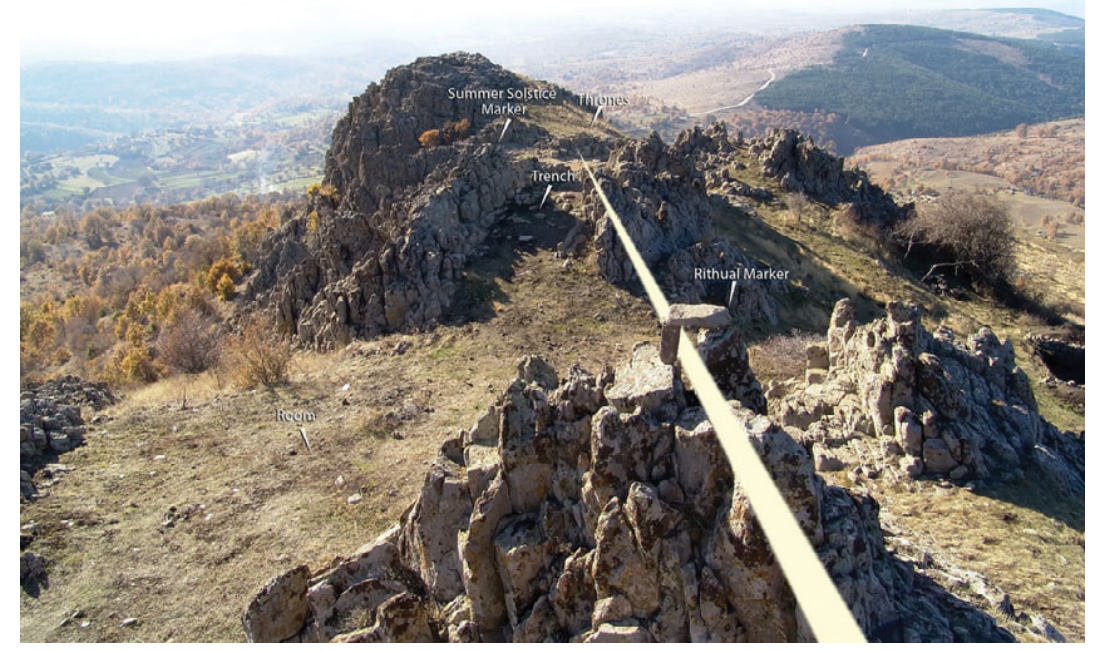

Figure 10. Path of the sunray in the day when end of the harvest is celebrated.

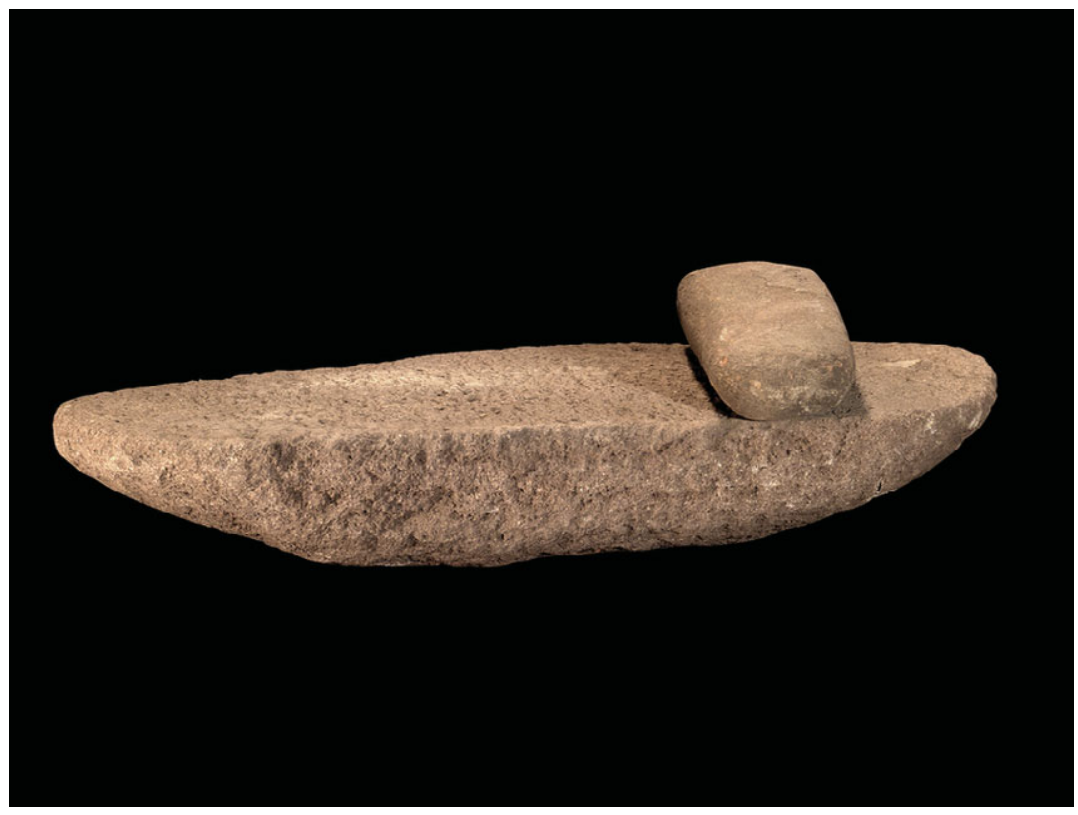

Figure 11. Hand mill.

\section{The rôle of Kokino in the Bronze Age agricultural community}

Combination of archaeoastronomical measurements and calculations, documented photographs produced, as well as artifacts found during the archaeological excavations in the past 7 years, unambiguously shows that the area right beneath the mountain peak was shaped and used as ancient observatory 4000 years ago. The role of the observatory was monitoring and predicting the Sun and Moon cycles of eclipse, development of a lunar 
calendar and monitoring annual movement of the Sun on the east horizon, but at the same time as a big sanctuary and place where ritual ceremonies were performed.

Time around 2000 BCE is known as early Bronze Age. This period in the science offers a very little data about the culture of human communities that lived in the central part of the Balkan Peninsula. Yet, contemporary studies and authors provide comparative methods and auxiliary sources (such as ethno astronomical data) for enlightening this relatively dark period of the development of the communities and cultures in this part of the world. Today, lots of researchers argue that the area encompassing East Mediterranean and Near East in pre-historic times and in ancient times should be considered as one and only unified cultural region. Recent studies (Johnston 2004; Kristiansen \& Larsson 2005) have shown that in this region rituals and myths regularly traveled from one to another culture. Even when completely different languages are spoken, inhabitants all over this region had similar outlook on the world and comparable ideals and lifestyles. Of course, every bigger group of people living on certain territory has its own pantheon, calendar of festivals, mythology and way of performing and worshiping cults, but yet, no fundamental difference can be traced among them.

In the region of East Mediterranean and Near East, during the Bronze Age, mountains were considered as center of the world (Kristiansen \& Larsson 2005). This concept, in its more developed form can be also found especially in the Minoan religion. Mountains are considered as axes of the world - axis mundi, connecting the sky and the earth. Man owns the land in order to transform the chaos of the cosmos in accordance with the laws of the Gods. As Gods are responsible for the cosmic order, people as their servants and collaborators should obey their orders, which provide equally well functioning of the world and human society (Eliade 1989). This means that the landscape is holy, but every place on it is at different level of holiness. Therefore, every ritual place, shrine or settlement has a structure that should be in accordance to the cosmic structure from the time of initial creation of Gods. Mountain peaks are places where people directly communicated with Gods, and thus the peak sanctuaries had high level of holiness and become big religious centers with specific, and multiply organization of the space. Moreover, the cult of the Cybele Goddess, known in the region of East Mediterranean and Asia Minor as a Great Mother is good example of the abovementioned. In the area of Ancient Greece in the period of 8 and 7 century BCE this Goddess was called Mountain Mother, or in Greek Meter Oreia. In Phrygia and Ancient Greece there was a wide spread cult concerning the mountain peaks, consisting of images or altars which were directly sculpted from so-called living rock (Johnston 2004). Later, this Goddess is presented as sitting in a stone throne.

For that reason, it can be said that Megalithic Observatory Kokino has all characteristics of one big mountain sanctuary and place where numerous religious ceremonies were performed. In addition, vast amount of artifacts excavated during the archaeological campaigns could confirm that this place had been visited by great number of people in the period from XX up to VII century BCE (Stankovski \& Trajkovska 2007).

Discovery of dual stone mould for casting bronze amulet and small ritual axe- celt (Fig. 12) affirms that people that lived in the close surrounding of the ancient observatory were familiar with the techniques for casting objects in bronze. Period around 2000 B.C. is known as a period with some kind different division of the community activities. Division on only male or female activities does not exist any more. There were people in the community with certain skills that gained special role and importance in regard to the life of the community. Emergence of handcraft and trade contributes to the emergence of elites (Childe 1930), and by this to the change in the organisation of the settlements and distribution of the power within the agricultural community. Community ruler has 


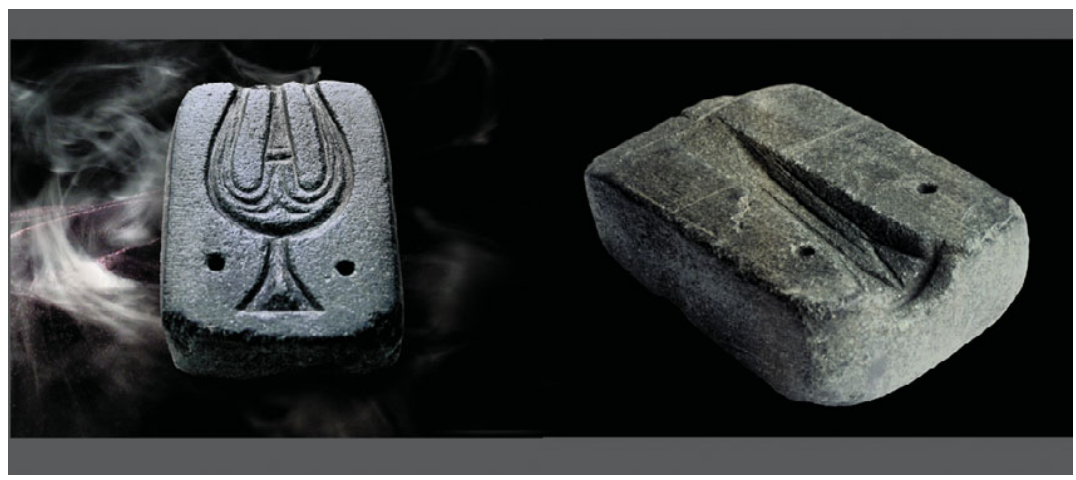

Figure 12. Stone mould for casting bronze amulet and small bronze ritual axe-celt.

a need to strengthen his power, thus he tends to presents his role as Gods will. Just for illustration, Sumerians thought that the kingdom is from haven and that it has divine origin (Eliade 1989). Sacramental nature of kings was expressed on various manners, but again he was not a God as in the time of Ancient Egypt and people did not pray to him. Nevertheless, his authority was big enough to mobilize great number of people to built huge megalithic monuments (Bogucki 1999). Ruler's energy was consumed during the year, and thus there was a need to perform various rituals and festivals in order to renew the holy power of the ruler.

Presented facts related to the ritual of renewal of the ruler's energy and power by ritual conjunction with the God Sun on the day when it was the end of the harvest, by all means affirm that rituals performed on the Megalithic Observatory Kokino are in compliance with the time and religious images of the people living in the wider region of East Mediterranean and Asia Minor.

Religious man recognizes division of holy and profane time. Holy time is the time when the Cosmos was created as an absolute creation of Gods. From that original times, Cosmos periodically renews, and therefore holy time is occurring repeatedly (Eliade 1972) or circularly, opposite to the profane time that is simply 'flowing' in one direction. It can be said that measurement of time is holy thing, because by exact determination of the time for performance of festivals and ritual timely and accurately cosmogony and renewal of the world is happening. Development of calendars, as well as the calendars themselves, bears sacral characteristics. For instance, in Syria and Canaan, as well as in many other ancient cultures, sacral calendar is the lunar calendar with lunar months, where the Young and Full Moon have special role, considered to be sacral (Johnston 2004).

This also explains the special constructed area and shape of the Ancient Observatory Kokino and its existence in unity with ritual places on the top of the mountain. Moreover, accurate development of a calendar had its own practical purpose first of all for the timely organization of the agricultural works. By simply staring a fire on the top of the mountain, a signal was sent to all people living in an area of $30 \mathrm{~km}$ suggesting that the day to start with some agricultural works had come, or that it is time to perform some religious rituals or festivals.

Knowledge about the cycles of Sun and Moon eclipses of course was extraordinary achievement of the ancient sky observers. Possibility to predict this frightening event, for the ordinary people, provided by all means special power to the people that developed the calendar, enabling them to gain special role and importance within the agricultural community that existed in the central part of the Balkan Peninsula in the period of 2000 BCE. 


\section{References}

Bogucki, P. 1999, The Origins of Human Society, (Oxford: Blackwell), p. 284

Cenev, G. 2002, National Museum Kumanovo, Museum Gazette, 8-9, 49

Cenev, G. 2004, The Sky over Macedonia (Skopje: MKC), p. 38

Cenev, G. 2006, Publications of the Astronomical Observatory of Belgrade, 80, p. 313

Cenev, G. 2007, Astrophysical Investigations, Institute of Astronomy at Bulgarian Academy of Science, 9,1

Cenev, G. 2008, Publ. Astron. Obs. Belgrade, 85, 87

Childe, V.G. 1930, The Bronze Age (Cambridge: Cambridge University Press)

Colton, R. \& Martin R.L. 1967, Nature, 213, 476

Eliade, M. 1972, Le Sacré et le Profane (Paris: Editions Gallimard)

Eliade M. 1989, Histoire des croyances et des idées religieuses (Paris: Payot)

Dordevič, N. 2003, Geological Reconnaissance of the Terrain on the Archaeological Localities around Kumanovo during Year 2002, Pyraichmes (Kumanovo: National Museum), II, 275

Hawkins, G.S. 1963, Nature, 200, 306

Hawkins, G.S. 1964, Nature, 202, 1258

Johnston, I.S. 2004, Religions of the Ancient World: a Guide (Cambridge: Harvard University Press)

Kristiansen, K. \& Larsson, B.T. 2005, The Rise of Bronze Age Society: Transmissions and Transformations (Cambridge: Cambridge University Press)

Stankovski, J., \& Trajkovska, L. 2007, Kokino fortress of the Sun (Kumanovo: Museum Kumanovo), p. 39 